\title{
TECTAL GLIOBLASTOMA
}

\author{
Feres Chaddad Neto', Armando Lopes², Mario Alberto Filho3, \\ Aguinaldo Catanoce ${ }^{4}$, Andrei Fernandes Joaquim", Evandro de Oliveira ${ }^{6}$
}

\begin{abstract}
Brain stem gliomas are a heterogeneous group of neoplasms arising mostly in paediatric patients. Tectal plate gliomas represent a particular type of brain stem tumours usually with a benign, indolent clinical course, presenting with signs of raised intracranial hipertension due to supra-tentorialhydrocephalous caused by aqueductal stenosis. Seldom high-grade lesions arise in this location with tremendous therapeutic implications. When a malignant tumour is clinically and radiographically suspected a biopsy should be performed to obtain histhological confirmation. Treatment is then planned in a case-by-case basis. We present the case of a glioblastoma of the tectal plate in a 22 years-old woman operated upon by a supracerebellar-infratentorial approach.
\end{abstract}

KEY WORDS: brain stem, tectal plate glioma, glioblastoma.

\begin{abstract}
Glioblastoma tetal
RESUMO - Os gliomas do tronco cerebral são um grupo heterogêneo de neoplasias que acometem habitualmente crianças. Os gliomas da placa quadrigeminal representam um tipo particular de tumores do tronco cerebral, habitualmente com um curso benigno e indolente, surgindo com sinais de hipertensão intracraniana devido a hidrocefalia supra-tentorial provocada por compressão do aqueduto cerebral. Raramente surgem lesões de alto grau nesta região, mas as implicações terapêuticas são tremendas. Quando existe suspeita clínica e imagiológica de que se trata de lesão maligna, esta deve ser biopsada para se obter confirmação histológica. O tratamento deve então ser planejado caso a caso. Apresentamos o caso de glioblastoma da placa quadrigeminal em uma paciente de 22 anos intervencionado por via supracerebelar-infratentorial.
\end{abstract}

PALAVRAS-CHAVE: tronco cerebral, glioma placa quadrigeminal, glioblastoma.

Brainstem tumours are usually described as paediatric neoplasms. In adults they are not so well known and account for less than $2 \%$ of gliomas'. The peak of incidence is the first decade in children and third and fourth decades in adults ${ }^{2}$. There are no significant clinical differences between the two groups with mean duration of symptoms being usually longer in adults. Survival may be significantly shorter in children with brain stem gliomas when compared with older patients. Histopathological analysis revealed grade II astrocytomas as the majority of gliomas in children and adults. The grade of brainstem glioma is a significant predictor factor for survival in adults, but in children it may not correlate with outcome ${ }^{2}$. Lowgrade gliomas tend to occur in the upper brain stem and high-grade tumours in its caudal portion. Tectal plate gliomas are a distinct group of midbrain tu- mours, usually with a benign course 3 . Periaqueductal location and absence of contrast enhancement and long periods of stability are classic features ${ }^{3}$. They have a better prognosis because of their non-infiltrative pattern and slow growth rate.

We report an illustrative case.

\section{CASE}

A 22 years-old woman, presented with insidious and low intensity generalized headache, together with paresthesis of the right body for the last month. MRI revealed an expansive, contrast-enhancing lesion located in the tectal plate, with supratentorial hydrocephalus. A neuroendoscopic ventriculostomy and biopsy were performed at another hospital. Histopathological analysis was consistent with glioblastoma (grade IV WHO astrocytoma). She did not undergo any complementary therapies.

At the time of consultation in our institution, six months

\footnotetext{
'Neurocirurgião do Instituto de Ciências Neurológicas, São Paulo, Brasil (ICNE), Neurocirurgião-Assistente da Disciplina de Neurocirurgia do Departamento de Neurologia da Universidade de Campinas, Campinas SP, Brasil (UNICAMP); ${ }^{2}$ Médico Residente do Centro de Neurocirurgia de Coimbra, Centro Hospitalar de Coimbra, Portugal; ${ }^{3}$ Neurocirurgião do Instituto de Ciências Neurológicas, São Paulo, Brasil (ICNE); ${ }^{4}$ Médico Residente do Instituto de Ciências Neurológicas, São Paulo, Brasil (ICNE); ${ }^{5}$ Médico Residente de Neurocirurgia da Universidade de Campinas, Campinas SP, Brasil (UNICAMP); ${ }^{6}$ Diretor do Instituto de Ciências Neurológicas, São Paulo, Brasil (ICNE); Professor e Chefe da Disciplina de Neurocirurgia da Faculdade de Ciências Médicas da Universidade Estadual de Campinas, Campinas SP, Brasil (UNICAMP).
}

Received 14 March 2007, received in final form 25 May 2007. Accepted 26 July 2007. 


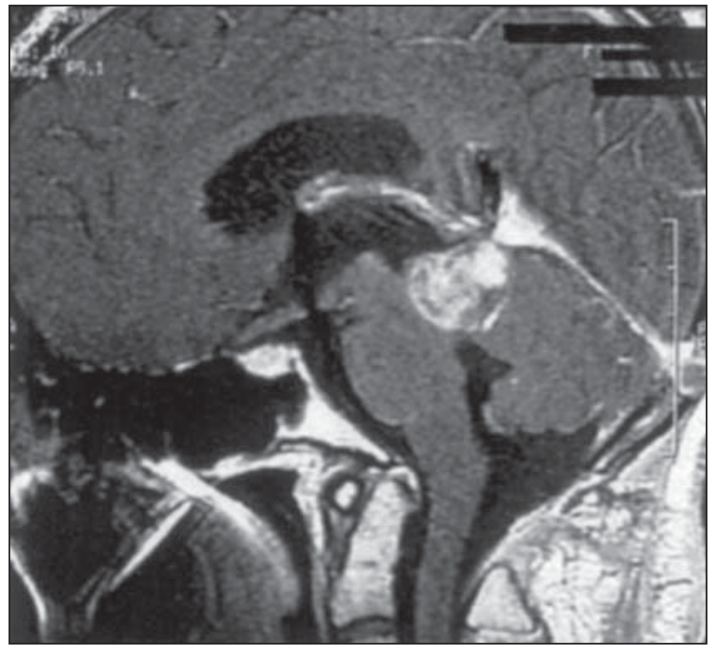

Fig 1. Pre-operative gadolinium enhanced sagital $T_{1} \mathrm{WI}$ revealing exophytic lesion in the tectal plate.

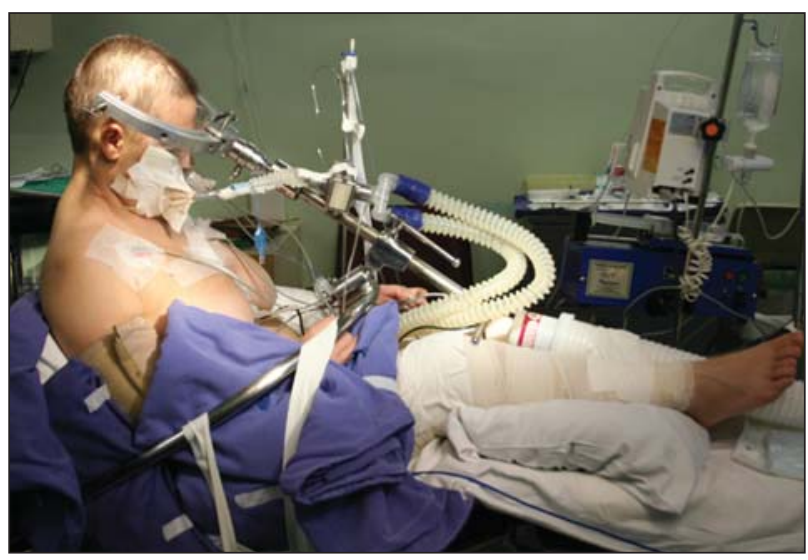

Fig 2. Semi-seatted position for a supracerebellar-infratentorial approach of the tectal plate. later, she presented with multidirectional nystagmus, visual impairment (greater on the right) and epicritic (thermo-algic) incomplete hemi-sensory loss on the right side, without any other neurological deficits. Pre-operative MRI showed an exophytic lesion in the tectal plate (Fig 1).

A ventricular-peritoneal shunt was placed and four weeks later a partial resection of the tumour was achieved by a supracerebellar-infratentorial mid-line approach. A complete third pair palsy on the right was the only side effect of the surgery (Figs 2 and 3 ).

Post-operative MRI showed partial removal of the tumour without complications (Fig 4).

Histhopatology continued to reveal a grade IV WHO astrocytoma.

She underwent complementary treatment with both radiotherapy and chemotherapy (temozolamide) and, six months after the procedure, she is clinically and neurologically stable.

\section{DISCUSSION}

Brainstem glioma, pilocytic astrocytoma and medulloblastoma are the most frequent infratentorial tumours in patients under 18 years ${ }^{4}$ representing $10-30 \%$ of brain tumours in children. They are usually infiltrative lesions and only a small number (dorsal exophytic) have a favourable prognosis. They occur mostly in childhood and adolescence $(77 \%$ in ages below 20 years), representing $1 \%$ dos tumours in adults ${ }^{5}$.

Midbrain tumours are a heterogeneous group of neoplasms with variable clinical and radiological features, relating with the location and tumour histology ${ }^{6}$. They occur in the tectal plate, tegmentum, invading the pons or cerebral aqueduct. Sometimes

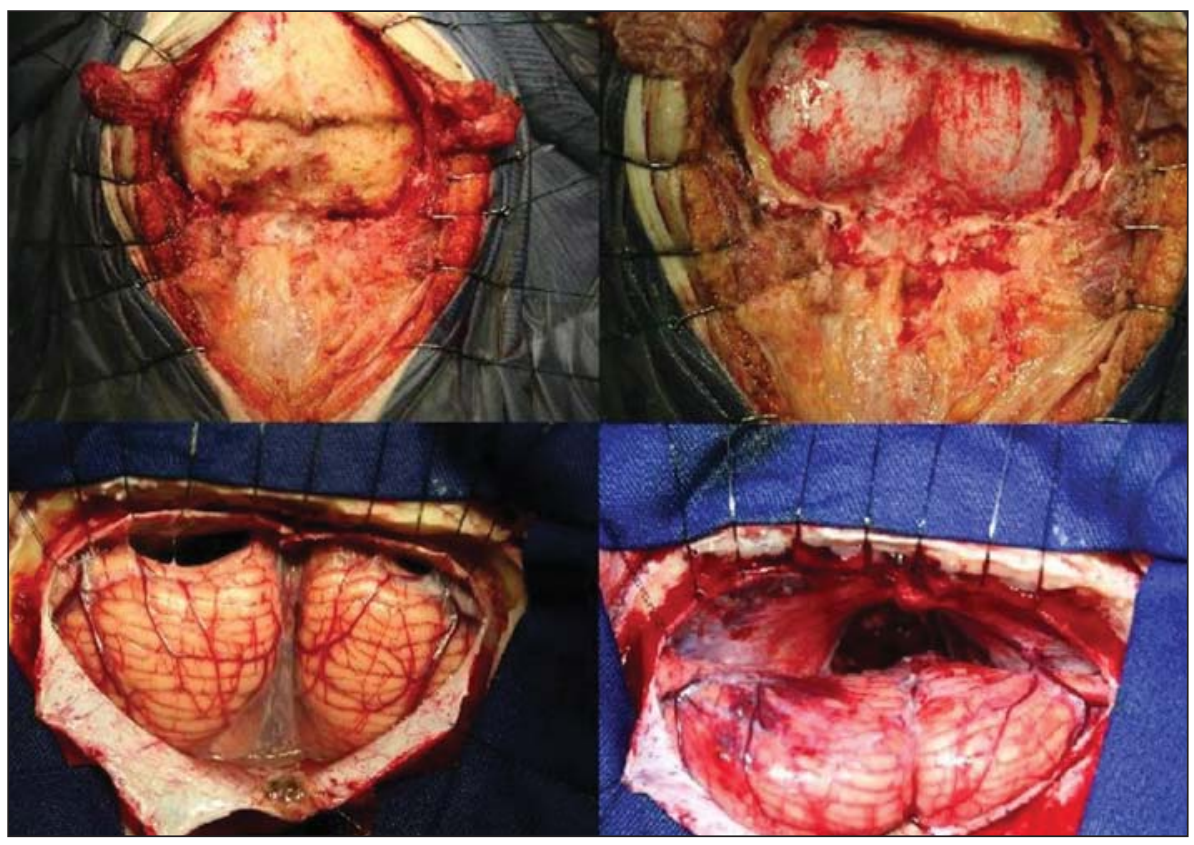

Fig 3. Supracerebellar-infratentorial approach to the tectal plate, through a sub-occipital mid-line craniotomy. 


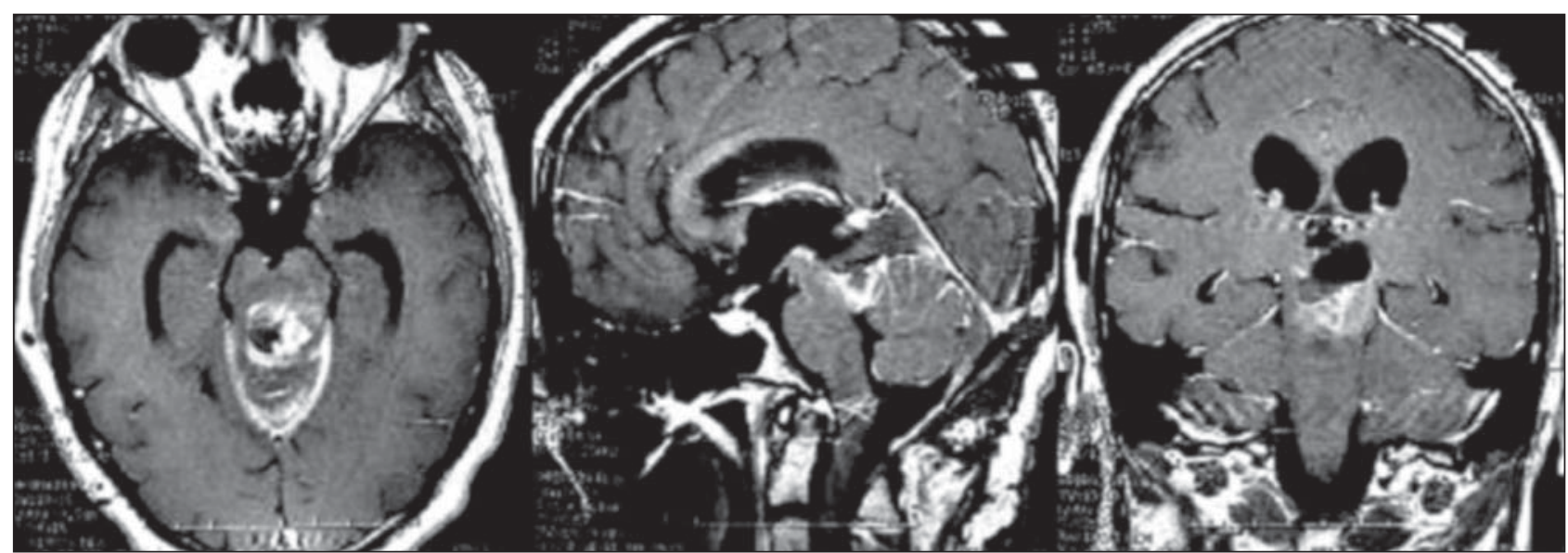

Fig 4. Post-operative axial, sagital and coronal, contrast enhanced, T1WI MRI, revealing partial resection of the lesion.

they represent midbrain invasion by tumours of adjacent regions, namely pineal and thalami ${ }^{6}$.

Tectal gliomas are in majority low-grade astrocytomas, considered a "benign" sub-group of brain stem gliomas. They represent approximately $10 \%$ of brain stem gliomas in children ${ }^{7}$ and $6 \%$ of paediatric brain tumours surgically treated.

Computhorized tomography (CT) reveals the hydrocephalous but may not be able to detect tectal plate tumours in up to $50 \%$ of patients. Calcifications are seen in 9-25\% of cases $^{8}$. Magnetic resonance imaging (MRI) is the chosen exam for diagnosis and follow up of tumours in this location. It allows a precise evaluation of the growth pattern and correct preoperative diagnosis in most of cases ${ }^{6}$. Gadolinium enhancement, calcifications, cysts e exophytic nature are observed in both low and high-grade gliomas ${ }^{8}$. They are typically isointense in $\mathrm{T} 1 \mathrm{WI}$ and iso or hiperintense in $\mathrm{T}_{2} \mathrm{Wl}$. Enhancement after endovenous contrast enclosures an undefined pathological significance. In the case of intrinsic tectal tumours, low-grade astrocyto$\mathrm{ma}$ is the probable diagnosis. Differential diagnosis of exophytic tectal tumours includes pineal neoplasms, requiring histological verification ${ }^{8}$.

Since biopsy is not performed upon many lesions, a precise statistic analysis is not possible.

They are mainly astrocytomas (pilocytic astrocytoma, WHO II difuse astrocytoma, anaplastic astrocytoma, high-grade astrocytoma) but other lesions have been identified (oligodendroglioma e oligoastrocytoma, WHO II ependymoma, ganglioglioma, medulloblastoma, primitive neuroectodermal tumours, disembryoblastic neuroepithelial tumours, metastasis, melanoma, lipoma, cavernoma, abcess and periaqueductal gliosis).
Many neurosurgeons perform a stereotactic biopsy to obtain histopathological confirmation of a low-grade tumour and only then the treatment is planned $^{2}$.

Clinical presentation with signs of raised intracranial pressure due to cerebral aqueduct compression resulting in supratentorial hydrocephalous is the most common clinical feature affecting all patients in some series $^{9}$. Focal neurological findings are less frequent (as diplopia, visual field defects, nystagmus, Parinaud syndrome, seizures) and usually revert after correction of the hydrocephalous.

It is not universally accepted that lesions with radiographic progression need to be treated. Paediatric tectal plate gliomas are usually low-grade tumours that can be managed conservatively even in the presence of radiographic enlargement, reserving radiotherapy and chemotherapy for clinical progression ${ }^{3}$ which is described in $15-25 \%$ of cases. It is even more advantageous to observe these patients in order to avoid radiation therapy and chemotherapy induced neurodevelopmental and endocrinal injury to the developing brain?.

The initial treatment is directed to correction of hydrocephalous. Ventricular-peritoneal shunt placement has good long-term results, if no dysfunction is verified. Third endoscopic ventriculostomy suppresses the need for shunt placement and a biopsy can be performed through an enlarged foramen of Monro. It allows resolution of signs and symptoms and the return of the ventricular system to its normal size. It is the procedure of choice for paediatric patients. Endoscopic aqueductoplasty with flexible systems (stent based or not) may be an option for some cases, but its long-term results are unknown. 
Due to its indolent course, open surgery is not usually indicated for low grade tumours. However, if a malignant, secondary or vascular lesion is clinically and radiographically suspected a microsurgical procedure should be performed.

Simple stereotactic aspiration of cystic brain stem gliomas is not an effective treatment strategy, because they will frequently recur leading to progressive neurological deficit. When combined with stereotactical placement of intra-cyst catheters, intracavitary irradiation with radioactive solutions, external radiotherapy and chemotherapy, it may allow cyst control without permanent morbidity or mortality ${ }^{10}$.

Resection or open biopsy of tumours in this location can be achieved by a supracerebellar-infratentorial or suboccipital-transtentorial approach, with the extent of removal being wider at the level of the superior colliculi and limited at the inferior colliculi due to high auditory risk ${ }^{9}$. Parinaud syndrome is one of the most frequent surgical complications. Auditory hallucinations and acoustic neglect syndrome can also occur. Despite of that, tectal plate region is a safer surgical field than the ventral midbrain.

Early and middle-latency brain stem auditory evoked potentials should be used for functional brainstem evaluation ${ }^{11}$ and definition of resection margins during tectal plate surgical procedures.

Stereotactic radiosurgery can be employed on tumour progression but due to radiation side effects the dosage is limited.

Optimal treatment of tectal plate gliomas is still to be determined. The role of different treatment modalities is unclear and universally accepted guidelines are still to be proposed. Serial neurological / clinical observations and MRI scans each 6-12 months is an option.

Patients with well-differentiated brainstem gliomas may be cured by microsurgical resection ${ }^{12}$.
Like in all high grade gliomas, resection of the tumour instead of biopsy, age equal or less than 6o years and a Karnofsky scale of 70 or greater are all correlated with better outcome.

Neuroanatomy based craniotomy for tumour resection is the mainstream of treatment currently available if it can be done safely, without further neurological deficits. However, surgical resection alone does not cure malignant brain tumours unless it is coupled with other treatment modalities addressed to the diffuse nature of these lesions, like chemotherapy and/or immunotherapy.

In high-grade gliomas, like the case presented, partial resection may prolong survival and facilitate subsequent complementary therapeutics

\section{REFERENCES}

1. Lázaro BC, Landeiro JA. Tectal plate tumours. Arq Neuropsiquiatr 2006; 64:432-436.

2. Selvapaudian S, RajshekharV, Chandy MJ. Brainstem glioma: comparative study of clinico-radiological presentation, pathology and outcome in children and adults. Acta Neurochir (Wien) 1999;141:721-726; discussion 726-727.

3. Daniel CB, Christos G, Leslie JA, et al. Tectal gliomas: natural history of an indolent lesion in pediatric patients. Pediatr Neurosurg 2000;32:24-29.

4. Section of Pediatric Neurosurgery of the American Association of Neurological Surgeons (ed.). Pediatric neurosurgery. New York: Greene and Stratton, 1982.

5. Packer RJ, Nicholson HS, Vezina LG, et al. Brain stem gliomas. Neurosurg Clin N Am 1992;3:863-879.

6. Sun B, Wang CC, Wang J. MRI characteristics of midbrain tumours. Rev Neurol 1996;24:73-76

7. Bowers DC, Georgiadis C, Burger PC, Melhem E, Cohen KJ. Tectal gliomas: radiographic progression does not mandate clinical intervention. Meeting abstract - 1999 ASCO Annual Meeting

8. Bognar L, Turjman F, Villanyi E, et al. Tectal plate gliomas. Part II: CT scans and MR imaging of tectal gliomas. Acta Neurochir 1994;127:48-54.

9. Lapras C, Bognar L, Turjman F, et al. Tectal plate gliomas. Part II: CT scans and MR imaging of tectal gliomas. Acta Neurochir 1994;126:76-83.

10. Hood TW, McKeever PE. Stereotactic management of cystic gliomas of the brain stem. Neurosurgery 1989;24:373-378.

11. Fischer C, Bognar L, Turjman F, Villanyi E, Lapras C. Auditory early and middle-latency evoked potentials in patients with quadrigeminal plate tumours. Neurosurgery 1994;35:45-51

12. Wang CC, Zhang JT, Liu AL. Surgical management of brain stem gliomas: a retrospective analysis of 311 cases. Zhongguo Yi Xue Ke Xue Yan Xue Bao 2005;27:7-12. 